University of Texas Rio Grande Valley

ScholarWorks @ UTRGV

$4-11-2014$

\title{
Visual Responses of Adult Asian Citrus Psyllid (Hemiptera: Liviidae) to Colored Sticky Traps on Citrus Trees
}

Mamoudou Setamou

A. Sanchez

R. R. Saldaña

J. M. Patt

Kenneth R. Summy

The University of Texas Rio Grande Valley

Follow this and additional works at: https://scholarworks.utrgv.edu/bio_fac

Part of the Biology Commons, and the Fruit Science Commons

\section{Recommended Citation}

Sétamou, M., Sanchez, A., Saldaña, R. et al. Visual Responses of Adult Asian Citrus Psyllid (Hemiptera: Liviidae) to Colored Sticky Traps on Citrus Trees. J Insect Behav 27, 540-553 (2014). https://doi.org/ 10.1007/s10905-014-9448-2

This Article is brought to you for free and open access by the College of Sciences at ScholarWorks @ UTRGV. It has been accepted for inclusion in Biology Faculty Publications and Presentations by an authorized administrator of ScholarWorks@ UTRGV. For more information, please contact justin.white@utrgv.edu,william.flores01@utrgv.edu. 
For Submission to:

Journal of Insect Behavior
Correspondence to:

Mamoudou Sétamou

Texas A\&M-Kingsville Citrus Center

312 N International Blvd

Weslaco, Texas, 78596

Tel: (956) 447-3370

Fax (956) 969-0649

E-mail: mamoudou.setamou@tamuk.edu colored sticky traps on citrus trees

${ }^{1}$ Corresponding author, Email: mamoudou.setamou@tamuk.edu

${ }^{2}$ U.S. Horticultural Research Laboratory, USDA, 2001 South Rock Road, Fort Pierce FL 34945

${ }^{3}$ Department of Biology, UTPA, 1201 W. University Drive, Edinburg, TX 78596 
12 Abstract The effects of five differently-colored sticky traps in capturing adult

13 Diaphorina citri were evaluated in citrus orchards. Trap catches of D. citri were

14 monitored fortnightly on blue, green, red, white and yellow sticky cards placed on three

15 citrus varieties during D. citri active flight period from April to July in south Texas.

16 Evaluation of mean trap catches of each color by repeated measures analysis of variance

17 produced three separate groups: yellow traps caught significantly more $D$. citri adults

18 than the other four traps; red and green traps caught significantly more $D$. citri than blue

19 and white traps, which were not significantly different. Although the number of adult

20 psyllid captured on all trap types significantly increased with time during the trapping

21 period, the performance of traps did not change with time. Trap catches were also

22 significantly influenced by the citrus species; traps placed on lemon trees captured more

23 D. citri than those placed on sweet orange and grapefruit, suggesting that plant preference

24 exhibited by $D$. citri may influence the performance of traps. The ratio of trap reflectance

25 between the 680 - to $700 \mathrm{~nm}$ and the $450 \mathrm{~nm}$ was significantly correlated with total trap

26 catches in all host species studied. Thus, this index was a good indicator of the

27 attractiveness of adult D. citri to colored traps. Additionally, we compared the reflectance

28 values of young versus mature flush shoots of the three host plants used in this study as

29 related to densities of $D$. citri recorded in colored traps. We discussed the importance of

30 visual cues in the host finding behavior of adult $D$. citri.

32 Key words: Diaphorina citri - citrus greening - colored traps - visual cues - reflectance 


\section{Introduction}

35 The Asian citrus psyllid, Diaphorina citri Kuwayama (Hemiptera: Liviidae), is

36 recognized as a great menace to U.S. citriculture. D. citri has invaded all U.S. citrus

37 producing states in the last decade (French et al. 2001, Halbert and Manjunath 2004,

38 Grafton-Cardwell et al. 2013). Because of its ability to transmit the bacteria Candidatus

39 Liberibacter-the putative causal agents of the deadly citrus greening disease

40 Huanglongbing-D. citri is an important pest of citrus (Bové 2006, Gottwald et al. 2007).

41 Huanglongbing is considered one of the deadliest diseases known to citrus in the world.

42 In 2005, Huanglongbing was detected in Florida (Halbert 2005), and over the last 6 years

43 has emerged as a damaging disease to the Florida citrus industry causing significant

44 economic losses in excess of $\$ 3.6$ billion (Hodges and Spreen 2012). Due to the lack of

45 any known cure, the nonspecific nature of disease symptoms that resemble many other

46 disorders, the prolonged latency of the disease in infected trees, and the difficulty of early

47 detection, Huanglongbing is a very difficult disease to manage (da Graça 1991). Limiting

48 the spread of the disease through vector control is one the viable approaches being

49 implemented for Huanglongbing management (Grafton-Cardwell et al. 2013). Effective

50 management of $D$. citri would however require efficient detection and monitoring tools to

51 be used to determine the presence of infestations and efficacy of control methods.

52 Several methods for monitoring D. citri populations have been reported such as

53 visual observation (Sétamou et al. 2008), trapping, tap sampling (Hall and Hentz 2009,

54 Flores et al. 2009), and vacuum sampling and sweep nets (Thomas 2012). Although no

55 consensus exists on the most effective method, colored sticky traps are widely used for $D$. 
56 citri detection and population monitoring in field studies. Colored traps are passive

57 methods of insect population studies that lure mobile stages of the insect onto a visual

58 target and their sticky surface arrest the insect. Their effectiveness is based on the visual

59 response of the target insect to the trap color. Insects use both visual and chemical stimuli

60 in locating their host plants (Bernays and Chapman 1994). The importance of each type

61 of cues depends on the insect species. However for herbivorous insects, plant spectral

62 quality comprising hue and intensity seems to be the most important factor for their

63 alignment and selection of living plants (Prokopy and Owens 1983).

64 The importance of visual stimuli in the behavior of D. citri and its response to light

65 and trap color has been reported (Hall et al. 2007, Wenninger et al. 2009, Sétamou et al.

66 2012). The preferences of different hues of green and yellow traps have been evaluated

67 by Hall et al. (2010). Furthermore Hall et al. (2007) reported that D. citri preferred

68 yellow over blue traps. However, there are no records on the spectral reflectance

69 characteristics that determine trap attractiveness to adult psyllids. Knowing the trap

70 reflectance parameters involved in D. citri host selection would facilitate the

71 development of effective traps for monitoring of its populations. Thus, the objectives of

72 this study were to evaluate the response of $D$. citri to a variety of colors, and to determine

73 the relative effect of their spectral reflectance parameters on the host finding behavior of

74 this psyllid.

76 Materials and Methods

77 Diaphorina citri population studies in the field 
78 Populations of $D$. citri adults were monitored using sticky traps in three contiguous citrus

79 blocks located at the TAMUK-Citrus Center from April to July 2007, to cover the first

80 two major flush cycles in citrus. The citrus blocks separated by $10-\mathrm{m}$ intervals of bare

81 soil, were managed using similar grove care practices. In each of the three rectangular

82 citrus blocks, respectively planted with grapefruit, lemon, or sweet orange, four replicates

83 of each of six color traps were used. Traps were made out of identical Oxford® paper

84 folder (Office Depot, Inc.) of assorted colors (black, blue, green, red, white and yellow),

85 laminated with clear plastic and coated on one side with tanglefoot ${ }^{\circledR}$ (Tanglefoot Co.,

86 Grand Rapids, MI) for capture of adult psyllids. One trap per color was placed along

87 each perimeter of each citrus block for a total of 4 traps per color. Thus, a total of 24

88 traps were deployed per citrus block. Between rows, traps were randomly assigned to the

89 first tree of six contiguous rows per citrus block, and along the rows traps were placed on

90 every $5^{\text {th }}$ tree. Traps were attached directly on a twig at the outer canopy of citrus trees at

$91 \approx 1.5 \mathrm{~m}$ above ground with the sticky surface facing outside; the between-row distance

92 was $4 \mathrm{~m}$ and the within-row distance between traps was $8 \mathrm{~m}$. Traps were replaced with

93 new ones every two weeks for the entire duration of study. During replacement, traps

94 were rotated and re-randomized to account for possible positional bias due to hotpots or

95 variation in psyllid field distribution. Recovered traps were brought to the laboratory and

96 evaluated under a stereomicroscope. The numbers of adult $D$. citri were counted and

97 recorded per trap and sampling date.

98 Measurement of trap and flush shoot spectral reflectance 
99 The reflectance of each color trap, and of newly emerged and mature flush shoots of the

100 three citrus species evaluated, namely grapefruit, lemon and sweet orange was measured

101 using a FieldSpec dual VNIR spectroradiometer sensitive in wavelengths extending from

102350 to 1100 nm with a ViewSpec Pro software (Analytical Spectral Devices, Inc.,

103 Boulder, CO). Each wavelength had a $10 \mathrm{~nm}$ bandwidth. A remote cosine receptor was

104 used to measure incident irradiation for calibration. Reference measurements were taken

105 on a Spectrolon (Analytical Spectral Devices, Inc., Boulder, CO) plate just prior to

106 measuring reflectance of traps, and converted to \% reflectance. Measurements of trap

107 reflectance were made on four ready to be deployed traps per color on clear sunny day on

1083 April 2007 between 10:00 and 13:00, while reflectance of three flush shoots for each

109 growth stage per host plant species were measured individually on 8 May 2007 between

$110 \quad$ 10:00 and 12:00. The spectroradiometer sensor had an $18^{\circ}$ field-of-view and

111 measurements were made by holding the sensor probe vertically ca. $5 \mathrm{~cm}$ above the trap

112 or leaf surface that was held horizontally flat on bare ground. Care was taken to prevent

113 any shadow on the illuminated area of the trap during measurement. Measurements of

114 spectral reflectance were evaluated only from 300 to $900 \mathrm{~nm}$ because this range covers

115 the sensitivity of conventional color.

116 Data analysis

117 A repeated analysis of variance was run to evaluate the effects of trap color, citrus host 118 species, time, and their interactions on $D$. citri trap catches using the PROC MIXED of

119 SAS (Littell et al. 1996). With the occurrence of significant $F$-values, the least square 
120 means of trap color and type of host plant were separated using Tukey test. Potential

121 relationships between cumulative trap catches for each color across all host plants and the

122 reflectance data at specific wavelengths and the indices derived were investigated by

123 calculating Pearson's correlation coefficients using the PROC CORR of SAS (SAS

124 Institute, 2001).

125 Reflectance values were derived and summarized for several wavelengths of the

126 electromagnetic spectrum including the $450 \mathrm{~nm}$ (visible blue), $550 \mathrm{~nm}$ (visible green),

$127680 \mathrm{~nm}$ (visible red), $700 \mathrm{~nm}$ (visible red edge) and $850 \mathrm{~nm}$ (near-infra red). In addition,

128 three indices comprising (1) the normalized total pigment to chlorophyll a ratio index

129 NPCI (NPCI = R680-R430)/(R680 + R430) (Peñuelas et al. 1994), (2) the simple ratio

130 between the visible red and the visible blue (R680/R450), and (3) the ratio between the

131 edge of visible red and the visible blue (R700/R450) were calculated. In plants, both the

$132 \mathrm{NPCI}$ and the R680/R450 are indices used to describe plant nutritional status. NPCI

133 varies with the ratio of total pigments to chlorophyll, indicative of plant phenology and

134 physiological status (Peñuelas et al. 1994), while the simple red-blue ratio index is the

135 ratio of carotenoid to chlorophyll content, and generally used as a measure of plant stress

136 (Carter 1994).

137 To determine the effect of trap color on reflectance values at specific wavelengths

$138(450,550,680$, and $850 \mathrm{~nm})$ and the three derived indices (NPCI, R680/R450, and

$139 \mathrm{R} 700 / \mathrm{R} 450$ ) data were subjected to one-way analysis of variance (ANOVA) using SAS

140 (SAS Institute, 2007). 
141 A linear regression analysis was conducted to determine the relationship between the

142 NPCI and R700/R450 indices and total numbers of $D$. citri caught on each color trap per

143 host plant. Numbers of $D$. citri captured were $\log (\mathrm{x}+1)$-transformed before analysis, but

144 only back-transformed means are presented.

145 The reflectance values of flush shoots were subjected to a two-way ANOVA to

146 evaluate the effects of citrus species and flush stage. Whenever significant $F$-values were

147 obtained, trap means were discriminated using the Student Newman Keuls test (Zar

148 1999).

149

150 Results

151 D. citri responses to colored sticky traps

152 Because all black traps discolored within a week of exposure in the field, trap catches of

153 this trap color were not considered in the analysis. All remaining traps retained their color

154 during the field exposure period, thus only data from these trap-colors were included in

155 the analysis. Captures of $D$. citri adults significantly varied with time, host plant species

156 on which traps were deployed, and trap color, but the interaction between time and trap

157 color, and trap color and host plant, respectively were not significant. This finding

158 suggests that color preference by adult psyllids did not change with time and host plant

159 (Table 1). Across all sampling dates and host plant species, the yellow trap caught a

160 significantly greater number of adult $D$. citri than any other color as shown by the higher

161 least square means (Table 2). The green and red traps had overall moderate trap catches, 
162 although at the peak period of $D$. citri flight, the red and the yellow traps had comparable

163 D. citri captures in the lemon grove (Fig. 1). The blue and white traps captured the fewest 164 numbers of $D$. citri adults throughout the study.

165 Counts of captured psyllids on all trap colors significantly increased with time from

166 April to July representing rapid build-up of $D$. citri populations from spring to summer in

167 Texas (Fig. 1). The significant host plant by time interaction suggested that $D$. citri

168 population dynamics varied with host plants. In this study, the highest $D$. citri captures

169 were observed in mid-July in both grapefruit and sweet orange blocks, while peak

170 captured were made in late-June to early July in the lemon block (Fig. 1). Population

171 fluctuations of $D$. citri are influenced by the flushing pattern of host plant with higher

172 populations observed during flush cycles than between flush cycles (M.S. unpublished 173 data).

174 The number of psyllid adults captured also varied significantly with the host plant in

175 which the traps were deployed (Table 1). Significantly more psyllids were captured on

176 traps placed in the lemon block compared to grapefruit and sweet orange. Mean psyllid

177 captured on lemon trees was 1.7 to 2.3 -fold higher than the mean numbers caught on 178 sweet orange and grapefruit, respectively. The lowest numbers of psyllid caught was on 179 traps deployed on grapefruit trees (Table 2).

180 Reflectance pattern of traps

181 The reflectance spectrum of the different traps was very unique for each color (Fig. 2).

182 There was a variation in the intensity of reflectance and the wavelength at which peak 
183 reflectance occurred (i.e. hue) with the trap color. The unsaturated white trap had a peak

184 reflectance $>75 \%$ at $\approx 420 \mathrm{~nm}$ and its reflectance stayed at around $70 \%$ between 500 and

$1851,000 \mathrm{~nm}$. In contrast, the black trap had a very low reflectance value $<10 \%$ between 300

186 and $700 \mathrm{~nm}$, and gradually increased exceeding $70 \%$ at $950 \mathrm{~nm}$. The blue trap had a

187 reflection in the range of 350 to $600 \mathrm{~nm}$ covering both the $\mathrm{UV}$ range $(350-450 \mathrm{~nm})$ and

188 blue range $(450-500 \mathrm{~nm})$ with peak value at $450 \mathrm{~nm}$. There was a reflectance in the 450

189 and $600 \mathrm{~nm}$ range from the green trap with a maximum at around $540 \mathrm{~nm}$. The red trap

190 had reflectance values $<25 \%$ between wavelengths of 400 and $560 \mathrm{~nm}$, then its

191 reflectance value gradually increased reaching a maximum value of $100 \%$ at $800 \mathrm{~nm}$

192 which remained steady up to $1,000 \mathrm{~nm}$. Reflectance values of the yellow trap gradually

193 increased from $450 \mathrm{~nm}$ and reaching a peak value of $80 \%$ at $800 \mathrm{~nm}$.

194 The mean light reflectance of the different traps at the five selected wavelengths and

195 the derived ratios are presented in Table 3. At the visible blue wavelength (450-500 nm),

196 the white trap had the highest reflectance value followed by the blue trap. The green and

197 yellow traps had similar and the lowest reflectance values at $450 \mathrm{~nm}$. In the green range

198 of 500-560 nm, the white, yellow and green traps had an average relative intensity of

199 reflectance higher than $40 \%$ while the blue, red and black traps had reflectance values

200 lower than 30\%. Within the visible red range $(635-700 \mathrm{~nm})$, the red, yellow and white

201 traps had higher reflectance values than the green, blue and black traps. The green and

202 blue traps had comparable reflectance values ranging from 15 to $20 \%$ in the visible red

203 range, but their intensity of light reflectance was significantly higher than that of the

204 black trap as shown by the SNK mean comparison method (Fig. 2, Table 3). The pattern 
205 of spectral reflectance was similar in the green, blue and black traps at $>700 \mathrm{~nm}$

206 wavelength.

207 The NPCI ratios of the green, red and yellow traps were positive, while the blue and 208 white traps had negative NPCI ratios. The red and yellow traps had higher NPCI values

209 than the other trap colors. The simple red-blue ratio (R700/450) index was highest for the

210 yellow color followed by the red color and lowest for the blue trap. The R700/450 ratio

211 index for the black and green traps had intermediate values, but was significantly higher

212 than 1, suggesting more visible red than visible blue reflectance in these traps.

213 Reflectance attributes of flush shoots

214 Reflectance spectrum of flush shoots varied with the flush stage with younger shoots

215 reflecting more light relative to mature shoots across all visible spectra for all three host

216 plant species (Fig. 3). Within the visible spectrum, peak reflectance of both stages of

217 flush shoots was observed in the green $(500-560 \mathrm{~nm})$ and yellow $(560-590 \mathrm{~nm})$ regions

218 for all three host plants. A two-way ANOVA of reflectance values at their peak (560 nm)

219 revealed that the effect of host plant species on shoot reflectance varied with the flush

220 shoot developmental stage $(F=17.43 ; \mathrm{df}=2,12 ; P<0.0001)$. With reflectance values $>$

$22120 \%$ at $560 \mathrm{~nm}$, no significant differences were obtained between the young shoots of the

222 three host plant species, while reflectance values of mature shoots $(<15 \%)$ varied

223 significantly with the host species. In mature shoots, lemon had the highest reflectance

224 values in the visible green and yellow regions, while no significant differences were

225 observed between grapefruit and sweet orange (Fig. 3). 
226 Relationship between color trap characteristics and D. citri captures

227 Because trap performance did not vary with host plant background or with time as shown 228 by the non-significant interactions (Table 1), and the same numbers of traps per color

229 were deployed and recovered in the three host plants, cumulative numbers of D. citri

230 captured across all host plants during the entire study period were calculated per trap

231 color. A total number of 1,192; 1,195; 1,660; 2,012; and 2,553 D. citri adults were caught

232 on the blue, white, green, red and yellow traps, respectively. Total numbers of D. citri

233 adults captured on traps were not significantly correlated with any of the individual

234 reflectance spectra at the blue, green, red and near-infra red regions (Table 4), suggesting

235 that it is difficult to use reflectance values at these single wavebands for predictions of

236 the trap performance in capturing D. citri adults. In contrast, positive and significant

237 relationships between the three derived indices and cumulative D. citri trap catches in all

238 host plants were found (Fig. 4) suggesting that these ratios are good descriptors of trap

239 performance in attracting $D$. citri.

\section{Discussion}

242 This study evaluated the attractiveness of various color traps to $D$. citri adults. Significant

243 differences were observed in the numbers of adults captured on various traps indicating

244 that $D$. citri perceived and distinguished between trap colors. The importance of visual

245 cues in host finding behavior of $D$. citri has been well established (Sétamou et al. 2012,

246 Hall et al. 2010, Wenninger et al. 2009). Throughout the study, the highest trap catches

247 were obtained with the yellow traps, followed by the red traps, while the blue and white 
248 traps had the lowest numbers of adults caught and the green trap had moderate values

249 (Table 2). With the exception of the white trap, all effective traps had higher cumulative

250 reflectance values across the visible wavelengths (Fig. 2). Specifically in the orange (590-

$251635 \mathrm{~nm})$ and the red $(635-700 \mathrm{~nm})$ wavelength regions (Hall et al. 2010), the reflectance

252 values of the yellow and red were significantly higher than the green and blue traps. In

253 the yellow wavelengths $(560-590 \mathrm{~nm})$ where the yellow trap has its peak reflectance in

254 the visible spectrum, reflectance values of the red trap also gradually increased from 16

255 to $40 \%$ (Table 3). The higher numbers of $D$. citri captured on the yellow and red traps

256 suggest that $D$. citri have a preference for trap with high reflectance values at wavelength

257 higher than $560 \mathrm{~nm}$. Hall et al. (2010) reported that D. citri trap captures tend to increase

258 with an increase in reflectance values in the yellow, orange and red regions as well as

259 increases in the ratios of red or yellow to blue. In the present study, no significant

260 relationships were obtained between $D$. citri trap catches and reflectance values of any of

261 the primary colors (blue, red and green) suggesting that none of the reflectance values of

262 these primary colors was a good predictor of $D$. citri trapping efficiency. However, the

263 derived ratios i.e. the normalized pigment chlorophyll index (NPCI) and the simple red-

264 blue ratio indices, which are indicators of plant health and stress (Carter 1994, Peñuelas

265 et al. 1994, Lichtenthaler et al. 1996, Peñuelas and Filella 1998) were good descriptors

266 of the attractiveness of color traps to $D$. citri. The positive and significant relationship

267 between the simple red-blue indices (R680/R450 and R700/R450) and the total number

268 of $D$. citri captured on traps suggest that these ratios may play an important role in adult

269 host finding behavior in this insect. 
270 The attractiveness of the red trap tested in this study is hard to explain, however, the

271 increase in reflectance in the yellow region of this trap may be a factor leading to adult $D$.

272 citri attraction to this trap color. Very few studies have reported attraction of hemipteran

273 insects to red traps (Döring and Chittka 2007, Straw et al. 2011, Rodriguez-Saona et al.

274 2012). In most of those studies where aphids and leafhoppers were attracted to red-

275 colored traps, the red color used had relatively higher reflectance values in the yellow

276 wavelengths as in this study. It is also possible that $D$. citri adults may have

277 photoreceptors that are tuned to red substrate color. An observation of adult psyllid eyes

278 suggests the presence of several red pigments that could be a physiological artifact

279 leading to this insect attraction to red substrate. Color attraction of $D$. citri adults may be

280 associated with their most preferred feeding sites in their host plants. In nature, D. citri

281 preferentially select juvenile over mature flush shoots of its rutaceous host plants for

282 feeding and reproduction (Hussain and Nath 1927), and these young shoots have higher

283 reflectance values than mature shoots in the yellow, orange and red wavelengths (Fig. 3).

284 No studies have been performed on the visual physiology of $D$. citri, but strong

285 positive responses to light (Wenninger et al. 2009, Sétamou et. 2012) and color (Sanchez

286 2008, Hall et al. 2010) have been reported. The different responses of D. citri to various

287 trap colors in this study support the idea visual cues are very important and even

288 necessary in D. citri host finding behavior.

289 The trapping efficiency of the tested traps was also significantly affected by the

290 background crop. Traps deployed on lemon caught the highest numbers of D. citri

291 followed by those on sweet orange, while traps placed on grapefruit caught the lowest 
292 numbers of psyllid adults. These results are consistent with previous studies that reported

293 higher D. citri populations on lime and lemon followed by sweet orange and grapefruit,

294 respectively (Arredondo 2009). One of the obvious differences in comparing various

295 mature and healthy citrus groves is their color appearance. Lemon leaves appear a light

296 yellow-greenish in contrast to the dark green color of sweet orange and grapefruit

297 (Turrell et al. 1961). In the present study, mature lemon leaves had higher reflectance

298 values in the whole visible spectrum than grapefruit and sweet orange (Fig. 3) despite

299 receiving similar management and grove care practices. This variation in appearance of

300 citrus species may lead to differential attraction and colonization of adult psyllids into

301 groves, thus explaining the higher $D$. citri populations in lemon relative to grapefruit and

302 sweet orange. In the eucalyptus psyllids (Ctenarytaina eucalypti Maskell and $C$.

303 spatulata Taylor), Brennan and Weinbaum (2001) showed that adult psyllids were more

304 attracted to expanding and expanded juvenile leaves that are yellow-greenish in

305 appearance than the green adult leaves. In addition to color, differential attraction of adult

306 psyllids to the three citrus species could be due to differences in volatile profile

307 emanating from the host plants as $D$. citri has been shown to respond to its volatile cues

308 (Patt and Sétamou 2010).

309 Higher numbers of D. citri were observed in early summer than during spring. Higher

310 numbers of ovipositing females may have been present at the initiation of the late-spring

311 to early summer flush cycle, thus explaining the higher progeny production on this flush

312 cycle. The prevailing hot and humid conditions towards the end of spring and early

313 summer in south Texas may also have led to a greater reproduction, rapid development of 
314 D. citri, and faster population build-up on late spring to early summer flush shoots. The

315 temperature during this period lied within $25-30^{\circ} \mathrm{C}$, the range of optimum temperature for

316 D. citri (Liu and Tsai 2000, Hall et al. 2011).

317 Field population biology of D. citri in Texas is closely related to the phenology of

318 flush cycles in citrus trees with tree colonization and higher densities observed during

319 flush cycles (M. S., unpublished data). Since young flush shoots have a yellow-greenish

320 appearance than mature flush shoots and leaves, it is possible these young shoots are

321 visually more attractive than mature ones in addition to the attraction associated to their

322 volatiles (Patt and Sétamou 2010). The green traps tested in this study were similar in

323 color to mature leaves of sweet orange or grapefruit, thus probably explaining their lower

324 attractiveness to $D$. citri in comparison to yellow and red traps. The effectiveness of

325 yellow and red colored traps in capturing $D$. citri adults despite being deployed in the

326 highly attractive citrus hosts suggests that these colored traps may serve as suitable tools

327 for monitoring grove infestation and population densities of this pest. However, the high

328 correlation between cumulative trap catches and the NPCI and R700/R450 ratios opens

329 avenues into developing specific trap colors that mimic the color of young flush shoots

330 and that would be most attractive to $D$. citri adults.

332 Acknowledgements We thank Daniel Davila and Maggie Garcia for their assistance

333 with data collection, and Dr. John V. da Graça and Juan Carlos Melgar and two

334 anonymous reviewers for their comments and suggestions on earlier versions of the 
335 manuscript. Partial funding for the study was provided by the Texas Citrus Producers

336 Board.

337

338 


\section{References}

340 Arredondo IMJ (2009) Abundance and population dynamics of Asian citrus psyllid

341 Diaphorina citri Kuwayama (Hemiptera:Psyllidae) as affected by flush shoots in

342 different host plants. MS thesis, Texas A\&M University-Kingsville.

343 Bernays EA, Chapman RF (1994) Host-plant selection by phytophagous insects.

344 Chapman \& Hall, New York.

345 Bové, JM (2006) Huanglongbing: a destructive, newly-emerging, century-old disease of

346 citrus. J Plant Pathol 88:7-37

347 Brennan EB, Weinbaum SA (2001) Psyllid responses to colored sticky traps and the

348 colors of juvenile and adult leaves of the heteroblastic host plant Eucalyptus globulus.

$349 \quad$ Environ Entomol 30:365-370.

350 Carter GA (1994) Ratios of leaf reflectance in narrow wavebands as indicators of plant

$351 \quad$ stress. Int J Remote Sens 15:697-703.

352 da Graça, JV (1991) Citrus greening disease. Ann Rev Phytopathol 29:109-136.

353 Döring TF, Chittka L (2007) Visual ecology of aphids: a critical review on the role of

354 colors in host finding. Arthropod Plant Interact 1:3-16.

355 Flores D, Hall DG, Jenkins DA, Sétamou M (2009) Abundance of Asian citrus psyllid on

356 yellow sticky traps in Florida, Puerto Rico, and Texas citrus groves. Southwest

357 Entomol 34:1-11.

358 French JV, Khalke CJ, da Graça JV (2001) First record of the Asian citrus psylla,

359 Diaphorina citri Kuwayama (Homoptera: Psyllidae) in Texas. Subtrop Plant Sci

$360 \quad 53: 14-15$. 
361 Gottwald TR, da Graça JV, Bassanezi RB (2007) Citrus Huanglongbing: The pathogen

362 and its impact. Plant Management Network:

363 http:www.plantmanagementnetwork.org/sub/php/review/2007/huanglongbing/.

$364 \quad$ Accessed 14 August 2013.

365 Grafton-Carwell EE, Stelinsky LL, Stansly PA (2013) Biology and management of Asian

366 citrus psyllid, vector of the Huanglongbing pathogens. Ann Rev Entomol 58:413-432.

367 Halbert SE (2005) The discovery of Huanglongbing in Florida. In: Proceedings $2^{\text {nd }}$

368 International Citrus Canker and Huanglongbing research workshop. Florida Citrus

369 Mutual, Orlando, Florida, pp 50.

370 Halbert SE, Manjunath KL (2004) Asian citrus psyllid (Sternorrhyncha: Psyllidae) and

371 greening disease of citrus: a literature review and assessment of risk in Florida. Fla

$372 \quad$ Entomol 87:330-353.

373 Hall DG, Wenninger EJ, Hentz MG (2011). Temperature studies with the Asian citrus

374 psyllid, Diaphorina citri: cold hardiness and temperature thresholds for oviposition. J

$375 \quad$ Insect Sci 11:1-15.

376 Hall DG, Hentz MG (2010) Sticky traps and stem-tap sampling protocols for the Asian

377 citrus psyllid (Hemiptera: Psyllidae). J Econ Entomol 103:541-549.

378 Hall DG, Hentz MG, Ciomperlik MA (2007) A comparison of traps and stem tap

379 sampling for monitoring adult Asian citrus psyllid (Hemiptera: Psyllidae) in citrus.

$380 \quad$ Fla Entomol 90:327-334.

381 Hall DG, Sétamou M, Mizell III RF (2010) A comparison of sticky traps for monitoring

382 Asian citrus psyllid (Diaphorina citri Kuwayama). Crop Prot 29:1341-1346. 
383 Hall DG (2009) An assessment of yellow sticky card traps as indicators of the abundance

384 of adult Diaphorina citri (Hemiptera: Psyllidae) in citrus. J Econ Entomol 102:446-

$385 \quad 452$.

386 Hodges AW, Spreen TH (2012) Economic impacts of citrus greening (HLB) in Florida

387 2006/2007-2010/2011. The University of Florida/IFAS, FE903.

388 Husain MA, Nath D (1927) The citrus psylla (Diaphorina citri, Kuw.) [Psyllidae:

389 Homoptera]. Memoirs of the Department of Agriculture in India. Entomol. Series

$390 \quad 10: 1-27$.

391 Littell RC, Milliken GA, Stroup WW, Wolfinger RD (1996) SAS System for mixed

392 models. Cary, North Carolina.

393 Liu YH, Tsai JH (2000) Effects of temperature on biology and life table parameters of the

394 Asian citrus psyllid, Diaphorina citri Kuwayama (Homoptera: Psyllidae). Ann Appl

$395 \quad$ Biol 137:201-206.

396 Patt JM, Sétamou M, (2010) Responses of the Asian citrus psyllid to volatiles emitted by

397 the flushing shoots of its Rutaceous host plants. Environ Entomol 39:618-624.

398 Penuelas JJ, Gamon JA, Fredeen AL, Merino J, Field CB (1994) Reflectance indices

399 associated with physiological changes in nitrogen- and water-limited sunflower

$400 \quad$ leaves. Remote Sens Environ 48:135-146.

401 Peñuelas J, Filella I (1998) Visible and near-infrared reflectance techniques for

402 diagnosing plant physiological status. Trends Plant Sci 3:151-156.

403 Prokopy RJ, Owens ED (1983) Visual detection of plants by herbivorous insects. Ann

$404 \quad$ Rev Entomol 28:337-364. 
405 Rodriguez-Saona CR, Byers JA, Schiffhauer D (2012) Effect of trap color and height on 406 captures of blunt-nosed and sharp-nosed leafhoppers (Hemiptera: Cicadellidae) and 407 non-target arthropods in cranberry. Crop Prot 40:132-144.

408 Sanchez A (2008) Importance of visual stimuli and host plant odor in host finding by the 409 Asian citrus psyllid Diaphorina citri Kuwayama (Hemiptera: Psyllidae). MS thesis, 410 Texas A\&M University-Kingsville.

411 SAS Institute (2008) SAS Procedures Guide, Version 9.2. SAS Institute, Cary, North 412 Carolina.

413 Sétamou M, Sanchez A, Patt JM, Nelson SD, Jifon JL, Louzada ES (2012) Diurnal 414 Patterns of Flight Activity and Effects of Light on Host Finding Behavior of the 415 Asian Citrus Psyllid. J Ins Behav 25:264-276.

416 Sétamou M, Flores D, French JV, Hall DG (2008) Dispersion patterns and sampling 417 plans for Diaphorina citri (Hemiptera: Psyllidae) in citrus. J Econ Entomol 101: 478$418 \quad 1487$.

419 Straw NA, Williams DT, Green G (2011) Influence of sticky trap color and height above 420 ground on capture of alate Elatonium abietinum (Hemiptera: Aphididae) in Sitka $421 \quad$ spruce plantations. Environ Entomol 40:120-125.

422 Thomas D (2012) Comparison of Insect Vacuums for Sampling Asian Citrus Psyllid 423 (Homoptera: Psyllidae) on Citrus Trees. Southwest Entomol 37:55-60.

424 Turrell FM, Weber JR, Austin SW (1961) Chlorophyll content and reflection spectra of 425 citrus leaves. Bot Gaz 123:10-15. 
426 Wenninger EJ, Stelinski LL, Hall DG (2009) Role of olfactory cues, visual cues, and

427 mating status in orientation of Diaphorina citri Kuwayama (Hemiptera: Psyllidae) to

428 four different host plants. Environ Entomol 38:225-234.

429 Zar JH (1999) Biostatistical analysis. Prentice Hall, Upper Saddle River, New Jersey.

430 
431 Table 1. Repeated measures analysis of variance of adult D. citri trap catches as affected 432 by trap color, host plant and time.

\begin{tabular}{lcccc}
\hline \hline \multicolumn{1}{c}{ Effect } & Numerator DF & Denominator DF & Type III F & P > F \\
\hline Color & 4 & 5 & 13.06 & 0.007 \\
Host plant & 2 & 10 & 23.90 & 0.0002 \\
Time & 8 & 40 & 94.58 & $<0.0001$ \\
Color $\times$ Host plant & 8 & 10 & 0.70 & 0.69 \\
Color $\times$ Time & 32 & 40 & 0.77 & 0.77 \\
Host plant $\times$ Time & 16 & 80 & 1.91 & 0.038 \\
Color $\times$ Host plant $\times$ Time & 64 & 80 & 1.31 & 0.13 \\
\end{tabular}

433 
439 Table 2. Least square means of the trap color and host plant effects on $D$. citri trap

440 catches

\begin{tabular}{|c|c|c|c|c|c|}
\hline Effects & Estimates & $\begin{array}{l}\text { Standard } \\
\text { Error }\end{array}$ & DF & t-value & $P>|\mathbf{t}|$ \\
\hline \multicolumn{6}{|c|}{ Color Effect } \\
\hline Blue & 22.1 & 4.1 & 5 & 5.35 & 0.003 \\
\hline Green & 31.1 & 4.1 & 5 & 7.54 & 0.0007 \\
\hline Red & 37.3 & 4.1 & 5 & 9.03 & 0.0003 \\
\hline White & 22.1 & 4.1 & 5 & 5.36 & 0.003 \\
\hline Yellow & 47.3 & 4.1 & 5 & 11.46 & $<0.0001$ \\
\hline \multicolumn{6}{|c|}{ Host Plant Effect } \\
\hline Lemon & 47.2 & 2.9 & 18 & 17.0 & $<0.0001$ \\
\hline Grapefruit & 20.7 & 2.9 & 18 & 7.5 & $<0.0001$ \\
\hline Sweet Orange & 28.0 & 2.9 & 18 & 10.12 & $<0.0001$ \\
\hline
\end{tabular}

441

442 
443 Table 3. Mean reflectance values and indices ${ }^{1}$ of different traps used to monitor adult $D$.

$444 \quad$ citri populations in citrus orchards

\begin{tabular}{|c|c|c|c|c|c|c|c|}
\hline \multirow{2}{*}{$\begin{array}{l}\text { Trap } \\
\text { color }\end{array}$} & \multicolumn{4}{|c|}{ Narrow bands tested } & \multirow[t]{2}{*}{$\mathrm{NPCI}^{2}$} & \multirow{2}{*}{$\begin{array}{l}\text { R680/ } \\
\text { R4503 }\end{array}$} & \multirow{2}{*}{$\begin{array}{l}\text { R700/ } \\
\text { R450 }\end{array}$} \\
\hline & $450 \mathrm{~nm}$ & $550 \mathrm{~nm}$ & $680 \mathrm{~nm}$ & $850 \mathrm{~nm}$ & & & \\
\hline Black & $6.98 \mathrm{~d}$ & $6.81 \mathrm{e}$ & $8.82 \mathrm{~d}$ & $62.56 \mathrm{c}$ & $0.043 \mathrm{c}$ & $1.24 \mathrm{~d}$ & $1.42 \mathrm{~d}$ \\
\hline Blue & $34.23 \mathrm{~b}$ & $21.32 \mathrm{~d}$ & $14.78 \mathrm{c}$ & $67.78 \mathrm{c}$ & $-0.040 \mathrm{e}$ & $0.43 \mathrm{e}$ & $0.54 \mathrm{f}$ \\
\hline Green & $11.03 \mathrm{~cd}$ & $38.19 \mathrm{c}$ & $17.88 \mathrm{c}$ & $73.2 \mathrm{ab}$ & $0.24 \mathrm{~b}$ & $1.64 \mathrm{c}$ & $2.21 \mathrm{c}$ \\
\hline Red & $10.2 \mathrm{~cd}$ & $6.81 \mathrm{e}$ & $62.2 \mathrm{~b}$ & $83.1 \mathrm{a}$ & $0.72 \mathrm{a}$ & $3.54 \mathrm{~b}$ & $3.75 \mathrm{~b}$ \\
\hline White & $76.53 \mathrm{a}$ & $68.93 \mathrm{a}$ & $74.7 \mathrm{a}$ & $70.3 \mathrm{~b}$ & $-0.02 d$ & $0.93 \mathrm{~d}$ & $0.93 \mathrm{e}$ \\
\hline Yellow & $14.3 \mathrm{c}$ & $63.9 \mathrm{~b}$ & $75.4 \mathrm{a}$ & $80.0 \mathrm{ab}$ & $0.68 \mathrm{a}$ & $5.29 \mathrm{a}$ & $5.51 \mathrm{a}$ \\
\hline$F$-value & 333.6 & 347.4 & 106.7 & 8.5 & 774.79 & 372.26 & 417.11 \\
\hline $\mathrm{DF}$ & 5,12 & 5,12 & 5,12 & 5,12 & 5,12 & 5,12 & 5,12 \\
\hline$P$-value & $<0.001$ & $<0.001$ & $<0.001$ & 0.0012 & $<0.01$ & $<0.01$ & $<0.01$ \\
\hline
\end{tabular}

$445{ }^{\mathrm{I}}$ Means followed by the same letter within each column are not significantly different at $\mathrm{P}$

$446<0.05$ as separated by the Student Keuls Newman test.

$447 \quad{ }^{2} \mathrm{NPCI}=(\mathrm{R} 680-\mathrm{R} 430) /(\mathrm{R} 680+\mathrm{R} 430)$

$448{ }^{3}$ Ratio between the reflectance at $680 \mathrm{~nm}$ (red) and reflectance at $450 \mathrm{~nm}$ (blue)

$449{ }^{4}$ Ratio between the reflectance at $700 \mathrm{~nm}$ (near red edge) and reflectance at $450 \mathrm{~nm}$ (blue) 
453 Table 4. Matrix presenting Pearson's correlation values between total numbers of $D$. citri

454 captured per trap, trap spectral reflectance at primary colors and derived indices.

\begin{tabular}{|c|c|c|c|c|c|c|c|c|}
\hline & Total D. citri & $\mathrm{R} 450$ & R550 & R680 & $\mathrm{R} 850$ & NPCI & R680/ & $\mathrm{R} 700 /$ \\
\hline & & & & & & & $\mathrm{R} 450$ & $\mathrm{R} 450$ \\
\hline Total D. citri & 1 & $-0.69 n s$ & $0.08 \mathrm{~ns}$ & $0.44 \mathrm{~ns}$ & $0.86 \mathrm{~ns}$ & $0.89^{*}$ & $0.98 * *$ & $0.997 * *$ \\
\hline R450 & & 1 & $0.52 \mathrm{~ns}$ & $0.29 \mathrm{~ns}$ & $-0.62 n s$ & $-0.58 n s$ & $-0.57 \mathrm{~ns}$ & $-0.65 n s$ \\
\hline R550 & & & 1 & $0.49 \mathrm{~ns}$ & $-0.22 \mathrm{~ns}$ & $-0.03 n s$ & $0.13 \mathrm{~ns}$ & $0.09 \mathrm{~ns}$ \\
\hline R680 & & & & 1 & $0.54 \mathrm{~ns}$ & $0.57 \mathrm{~ns}$ & $0.58 \mathrm{~ns}$ & $0.50 \mathrm{~ns}$ \\
\hline R850 & & & & & 1 & $0.97 * *$ & $0.87 \mathrm{~ns}$ & $0.88^{*}$ \\
\hline NPCI & & & & & & 1 & $0.90 *$ & $0.92 *$ \\
\hline R680/R450 & & & & & & & 1 & $0.99 * *$ \\
\hline $\mathrm{R} 700 / \mathrm{R} 450$ & & & & & & & & 1 \\
\hline
\end{tabular}

$455 \mathrm{~ns}=$ non-significant $(\mathrm{P}>0.05), *=$ significant $(\mathrm{P}<0.05)$ and $* *=$ significant $(\mathrm{P}<0.01)$. 456

457 


\section{Captions for figures:}

459 Figure 1. Mean number of Diaphorina citri captured on various colored traps deployed 460 in three citrus groves (grapefruit, lemon and sweet orange) in south Texas from April to

461 July 2007. Values represent means of four traps per color in each of the host plant.

463 Figure 2. Reflectance spectra of colored traps used in Diaphorina citri trapping study in

464 grapefruit, lemon and sweet orange in south Texas, 2007. The spectrum of each color trap

465 is its reflectance relative to a white standard (99\% pure Spectralon calibrated reflectance

466 standard). Values are means of four traps measured per color.

468 Figure 3. Spectral reflectance curves for young and mature flush shoots of three citrus

469 species (grapefruit, lemon and sweet orange) in which Diaphorina citri population

470 dynamics were studied. Values are means of three flush shoots measured for each stage

471 per host plant.

472

473 Figure 4. Relationship between total trap catches of D. citri and derived spectral

474 reflectance indices of colored sticky cards $(\mathrm{NPCI}=[\mathrm{R} 680-\mathrm{R} 430] /[\mathrm{R} 680+\mathrm{R} 430]$,

$475 \mathrm{R} 680 / \mathrm{R} 450$ and R700/R450 are the simple ratios between the reflectance values of the

476 visible red $(680 \mathrm{~nm})$ and near red edge $(700 \mathrm{~nm})$ with the visible $(450 \mathrm{~nm})$, respectively. 477 

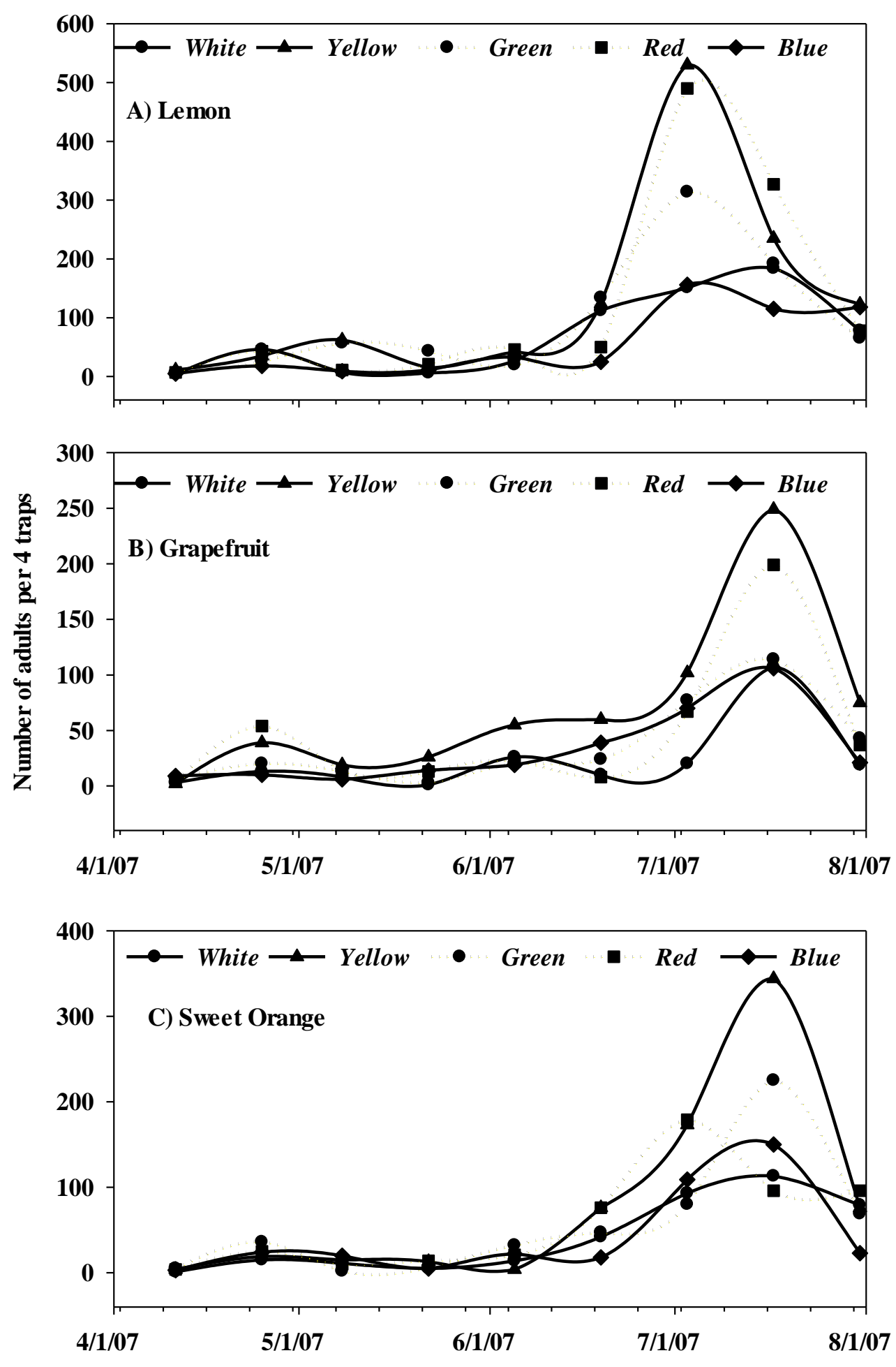


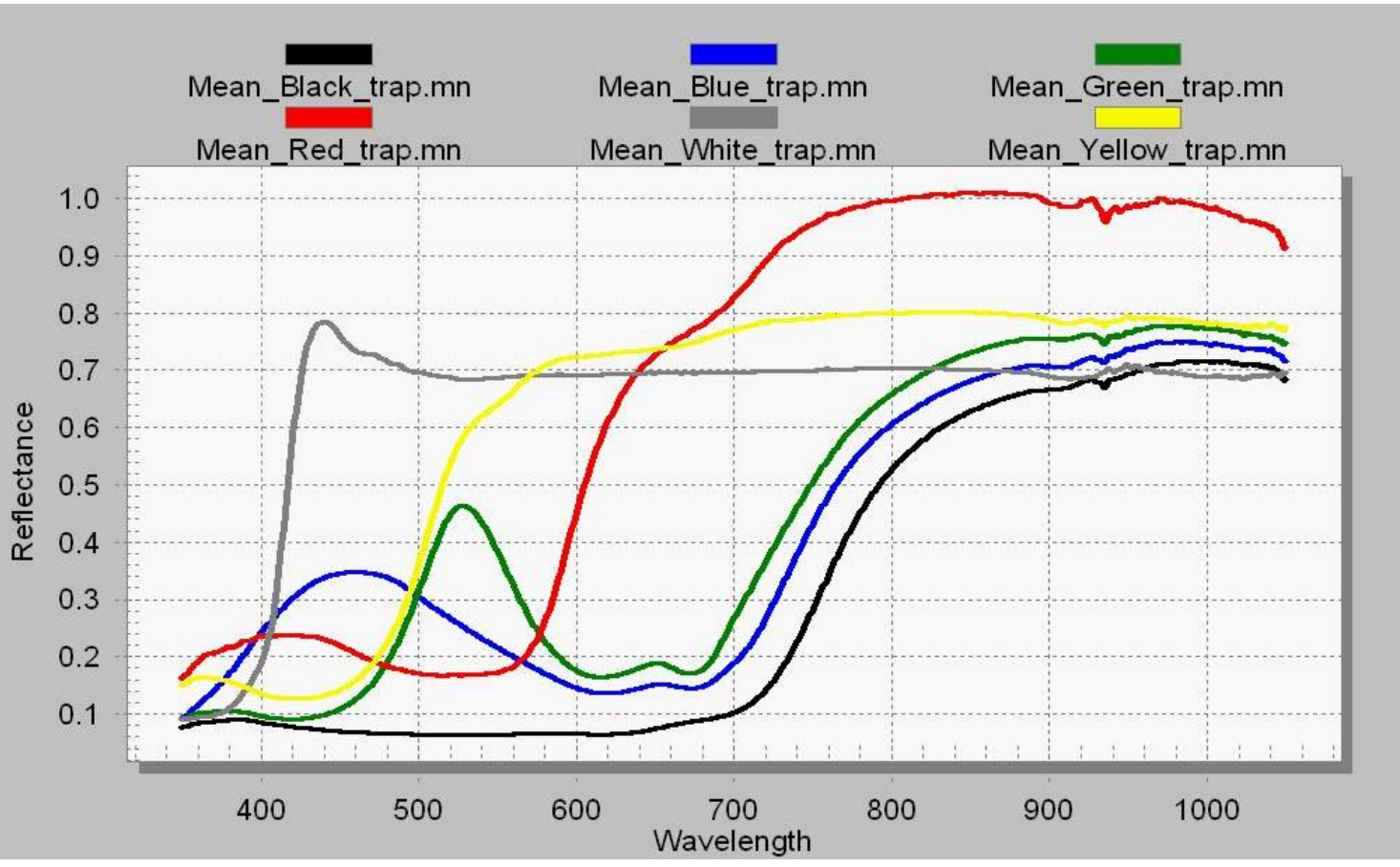

481

482 

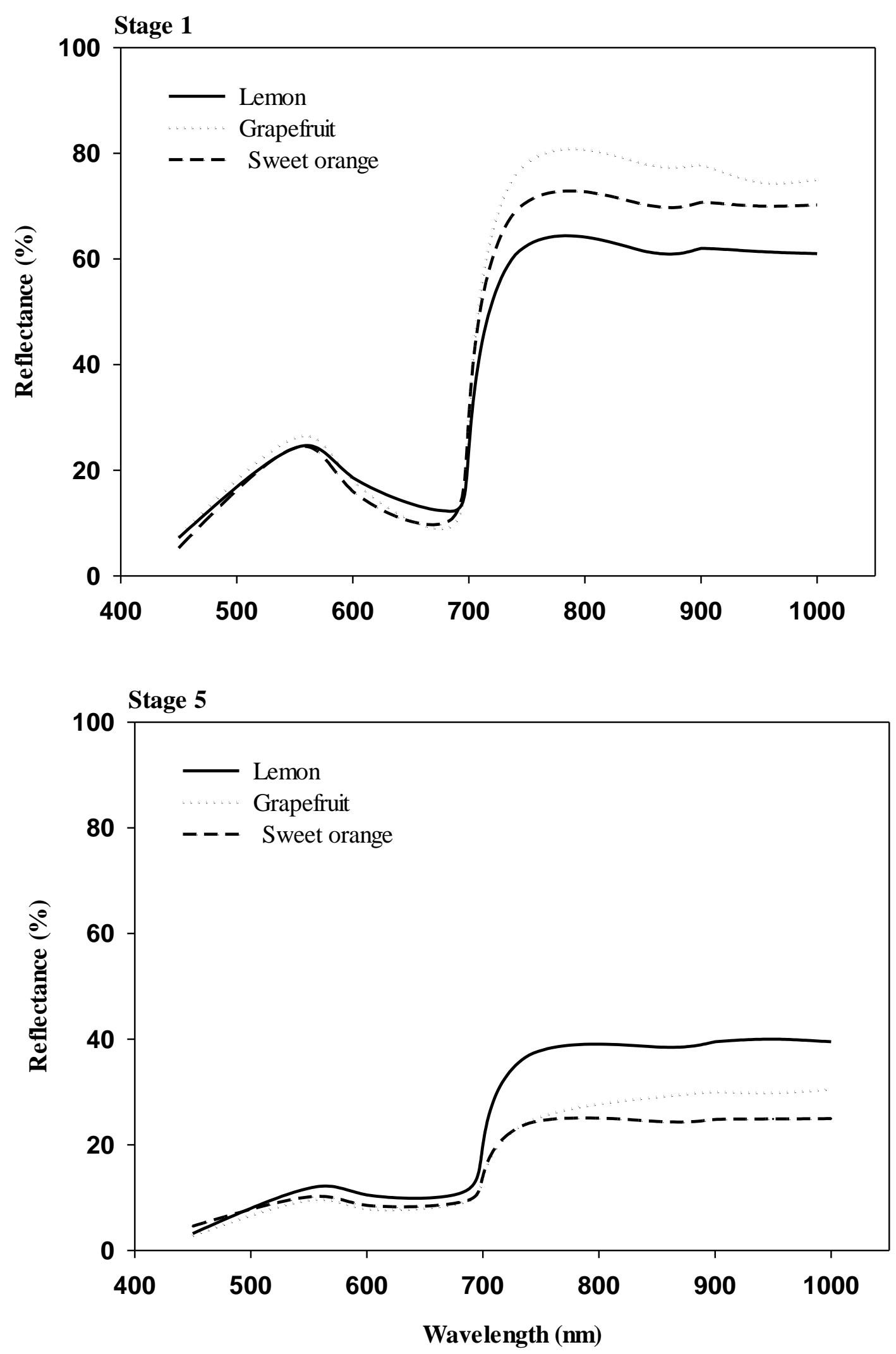

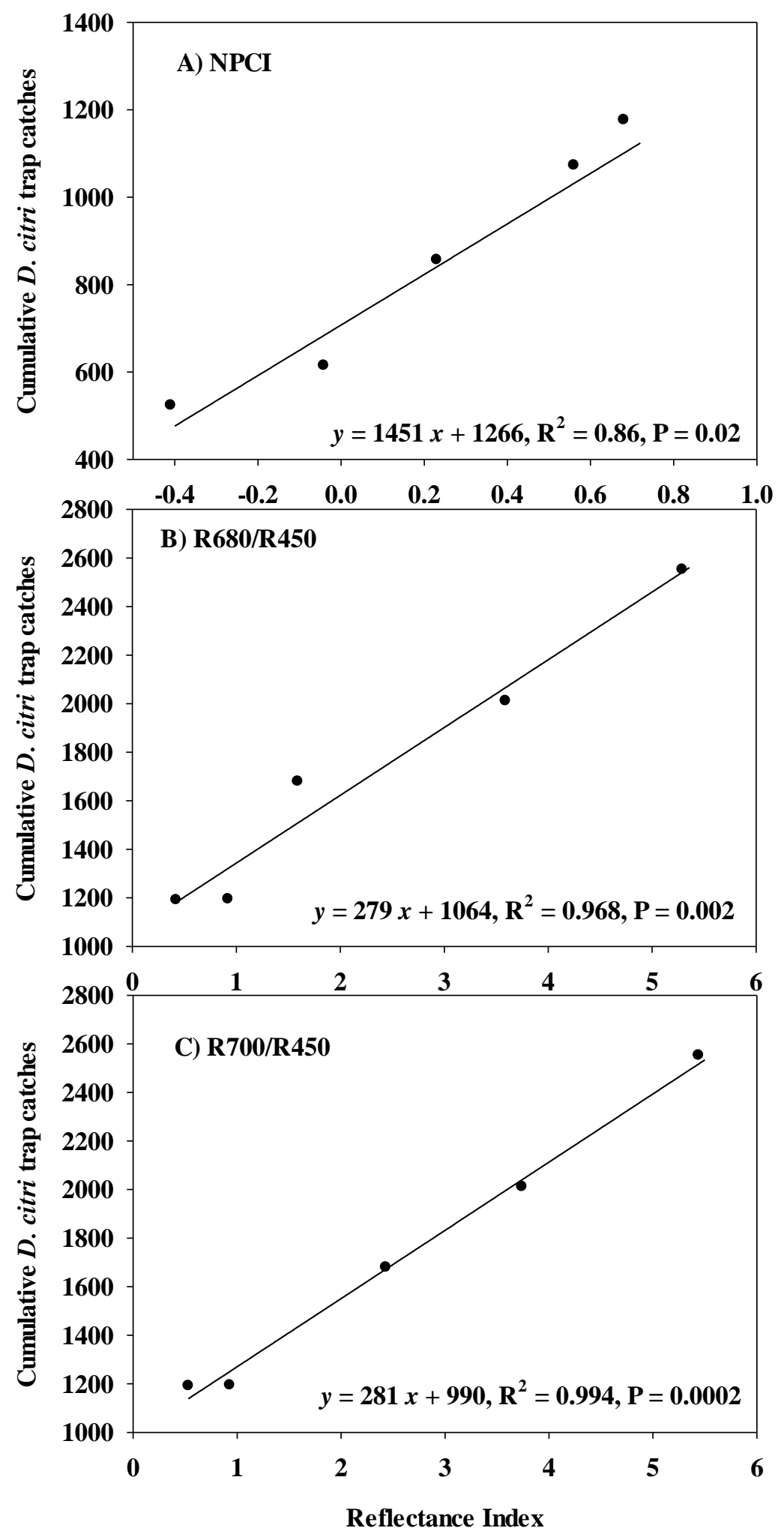